CLINICAL STUDY

\title{
Transsphenoidal pituitary surgery via the endoscopic technique: results in 35 consecutive patients with Cushing's disease
}

\author{
R T Netea-Maier ${ }^{1}$, E J van Lindert ${ }^{2}$, M den Heijer ${ }^{1}$, A van der Eerden ${ }^{1}$, G F F M Pieters ${ }^{1}$, C G J Sweep ${ }^{3}$, \\ $\mathrm{J}_{\mathrm{A}}$ Grotenhuis $^{2}$ and A R M M Hermus ${ }^{1}$ \\ ${ }^{1}$ Pituitary Centre Nijmegen, Department of Endocrinology ${ }^{2}$ Department of Neurosurgery and ${ }^{3}$ Department of Chemical Endocrinology, Radboud \\ University Nijmegen Medical Centre, Geert Grooteplein 8, 6500 HB, Nijmegen, The Netherlands
}

(Correspondence should be addressed to Romana T Netea-Maier; Email: R.Netea-Maier@endo.umcn.nl)

\begin{abstract}
Objective and design: The endoscopic technique has been recently introduced in the field of transsphenoidal pituitary surgery. This technique allows inspection of sellar, supra- and parasellar structures and removal of the tumor under direct visualization, is minimally traumatic and permits easier reoperations. This is the first report on the results of endoscopic surgery for patients with Cushing's disease. Our aim was to retrospectively analyze the results of pituitary surgery in 35 consecutive patients with Cushing's disease operated in our hospital after the introduction of the endoscopic technique (1998-2004).

Methods: Remission was defined as suppression of plasma cortisol $(\leq 50 \mathrm{nmol} / \mathrm{L})$ after $1 \mathrm{mg}$ dexamethasone overnight determined in the first 3 months after surgery and disappearance of clinical signs and symptoms of hypercortisolism. The patients were followed for an average of 27 months (range 4 to 81 months, median 20 months).

Results: Pituitary MRI showed a macroadenoma in 6 patients, a microadenoma in 17 patients and no adenoma in 12 patients. After the initial surgery 27 patients $(77 \%)$ were in remission. None of the patients had a relapse during follow-up. In the remaining 8 patients hypercortisolemia persisted after surgery. Three of them had a second endoscopic pituitary surgery resulting in remission in two patients. In one patient a second endoscopic pituitary surgery will soon follow. The remaining four patients were treated with radiotherapy postoperatively. Two of them were at the time of data collection in remission. One patient from the remission group had a serious epistaxis and three patients had cerebrospinal fluid leakage, one requiring an external lumbar drain, shortly after surgery. No complications were recorded in the failure group. Postoperatively $34 \%$ of all patients required substitution with levothyroxine, $40 \%$ required substitution with glucocorticoids, $17 \%$ received estrogens or testosterone and $6 \%$ still required desmopressin.

Conclusions: Endoscopic transsphenoidal pituitary surgery resulted in our series of patients with Cushings disease in an excellent postoperative remission rate. A randomized clinical trial, comparing endoscopic and conventional pituitary surgery in patients with Cushings disease, is needed to determine the pros and cons of both techniques.
\end{abstract}

European Journal of Endocrinology 154 675-684

\section{Introduction}

Hypersecretion of ACTH by a pituitary adenoma (Cushing's disease) is the most common cause of endogenous hypercortisolism. The condition is potentially life threatening and requires aggressive therapy. Transsphenoidal pituitary microsurgery is the treatment of choice for these patients. However, even in experienced hands no more than 50 to $90 \%$ of patients are in remission after surgery $(1-15)$. This may be due to the fact that ACTH producing adenomas are small and thus cannot be visualized, even with modern imaging techniques, making it difficult for the surgeon to find the adenoma. Moreover, hypercortisolemic patients are prone to complications during surgery (16). Longterm follow-up has shown that the quality of life of patients with Cushing's disease who are in remission after a first pituitary operation is better than in those patients who need additional treatment (17). Therefore, a successful initial pituitary operation is highly desirable for patients with Cushing's disease.

The endoscopic technique has been recently introduced in the field of pituitary surgery (18-23). Traditional surgical approaches to pituitary tumors are based on transseptal or sublabial transsphenoidal access to the sella turcica (20). The endoscopic 
endonasal approach avoids transseptal dissection, thus reducing patient discomfort and postoperative pain. The endoscope has increasingly been used in pituitary surgery since the mid 1990s either in conjunction with the microscopic technique (24) or as a pure endoscopic procedure $(18,25,26)$. Especially the better panoramic visualization of sellar, supra- and parasellar anatomy with increased illumination and magnification are recognized as major advantages offered by the endoscopic technique $(21,25,27)$. Some concerns have been raised regarding the lack of stereoscopic view with the endoscope and the lack of maneuverability as surgeons can only manipulate tools with one hand unless a holder is used, which in turn may crowd the operative field $(19,27,28)$. These disadvantages can, however, be reduced by using more refined instrumentation $(19,27)$. Initial reports showed a decrease in postoperative discomfort and hospitalization time as well as a quick recovery in patients operated by the endoscopic technique in comparison with the conventional microscopic technique $(25,29-31)$. Decreased operative time and decreased blood loss as compared with open transsphenoidal surgery have also been reported $(31-33)$. The endoscopic approach is safe, all authors reporting low complication rates $(25,26$, $30-35)$. It is minimally traumatic and permits easier reoperations $(18-21,23)$. This makes the endoscopic pituitary approach attractive for patients with Cushing's disease in an attempt to avoid bleeding complications that are particularly feared because of the hypercortisolemic status.

To our knowledge, there are no specific studies on the results of endoscopic pituitary surgery in patients with Cushing's disease. Endoscopic pituitary surgery was introduced in our hospital in 1997 and it has been applied in all patients with Cushing's disease treated in our centre since 1998. The aim of our study was to analyze retrospectively the results of pituitary surgery in the 35 consecutive patients with Cushing's disease who have been operated in our hospital after the introduction of the endoscopic technique (1998-2004).

\section{Patients and methods}

\section{Patients}

The medical records of the 35 consecutive patients with Cushing's disease undergoing endoscopic pituitary surgery in our hospital between 1998 and 2004 were analyzed. There were 25 females and 10 males, age at the time of diagnosis was $41.0 \pm 14.8$ years and BMI was $28.7 \pm 5.3 \mathrm{~kg} / \mathrm{m}^{2}$. We collected data on the preoperative and the early postoperative evaluation, on complications that occurred during the operation or in the early postoperative period and on the last evaluation at the most recent follow-up visit.

\section{Preoperative evaluation}

Diagnosis of hypercortisolism was based on clinical grounds and biochemical tests including repeated 24-h urinary free cortisol (UFC) measurements, assessment of the circadian rhythm of plasma cortisol with midnight plasma cortisol measurement and determination of plasma cortisol after overnight low dose dexamethasone (1 mg at $2300 \mathrm{~h}$ ) (36). Pituitary imaging by MRI with i.v. contrast (gadolineum) was performed in all patients. Six of the 35 patients had a macroadenoma (defined as $\geq 1 \mathrm{~cm}$ in diameter) on the preoperative MRI. In the other patients the MRI showed either a tumor $<1 \mathrm{~cm}$ (17 patients) or no evidence of a tumor (12 patients). In addition, the results of the CRH test (100 $\mu \mathrm{g}$ human CRH i.v.) (37), and the high-dose dexamethasone test ( $7 \mathrm{mg}$ dexamethasone in 7 hours i.v.) (38) were used to demonstrate the pituitary origin of the hypercortisolism. In 12 patients bilateral catheterisation of the inferior petrosal sinuses was performed with blood sampling before and after i.v. stimulation with $100 \mu \mathrm{g}$ human CRH (39), to confirm the pituitary origin of the hypercortisolism in all 12 patients.

\section{Treatment with cortisol lowering agents before surgery and with glucocorticoids in the perioperative period}

Treatment with cortisol lowering agents, metyrapone and/or ketoconazole, was given in 30 patients for a period of 4 months preoperatively. On the day of surgery, administration of glucocorticoids i.v. was started (prednisolone, $25 \mathrm{mg}$ every $8 \mathrm{~h}$ i.v. for two days) with the first dose one hour before the start of the operation. Thereafter, the dose of glucocorticoids was decreased rapidly (prednisolone orally $50 \mathrm{mg}$ on day 2, $25 \mathrm{mg}$ on day 3 and 4) during the next days so that the patients received the last dose of glucocorticoids as $10 \mathrm{mg}$ prednisolone orally on the fifth day postoperatively. Thereafter, no further glucocorticoids were administered until the seventh day postoperatively, after blood sampling for the first endocrine evaluation. The interval between the last dose of glucocorticoids and the first postoperative measurement of fasting plasma cortisol was at least $48 \mathrm{~h}$.

\section{Surgical technique}

Our technique is based on the pioneering work of Jho et al. $(22,23)$ and Cappabianca et al. $(18,19)$. However, we (EJvL and JAG) modified the technique by using a binostril, transsphenoidal, endoscopic approach to the sella turcica with a handheld endoscope.

The optic instrument used was a $5^{\circ}$ lensscope with a diameter of $4 \mathrm{~mm}$ and a separate shaft around it for irrigation and suction to clear the front lens. This instrument allows by its pistol grip an easy and comfortable handling (Richard Wolf GmbH, Knittlingen, Germany). The maximal outer diameter of the oval-shaped shaft is 
$6.3 \mathrm{~mm}$. A $25^{\circ}$ optic is available for use in specific situations.

The camera used is the Stereosite ${ }^{\mathrm{TM}}$ (Vista Medical Technologies Inc., Carlsbad, California, USA). This camera system incorporates a Head-Mounted Display (HMD) that is worn by the surgeon during all phases of the operation. The endoscopic picture is projected on LCD-screens from the HMD with a resolution of $640 * 480$ pixels. The instruments used are principally the same as those used during a conventional microsurgical procedure.

In cases where the tumor is identified by MRI or during the operation, selective adenomectomy is performed. In case of negative MRI investigations and a negative pituitary exploration, a hemihypophysectomy is performed, preferentially based on lateralization of ACTH levels during inferior petrosal sinus sampling. Only in cases of persisting hypercortisolism after surgery, a total adenohypophysectomy is performed in a second surgical procedure.

\section{Postoperative evaluation}

The early postoperative biochemical evaluation consisted of measuring the fasting $(0800 \mathrm{~h})$ plasma levels of ACTH and cortisol on the seventh day after surgery ( $48 \mathrm{~h}$ after the last dose of glucocorticoids). In patients with a basal plasma cortisol concentration below $200 \mathrm{nmol} / \mathrm{L}$ substitution therapy with hydrocortisone, $30 \mathrm{mg}$ once daily, or cortisone acetate, $37.5 \mathrm{mg}$ once daily, was prescribed. Patients were re-evaluated every 24 weeks during the first 3 months and thereafter at 2-3 months intervals during the first year after surgery and at least yearly thereafter. At each visit the fasting plasma cortisol concentration was measured after withdrawal of glucocorticoid substitution for $24 \mathrm{~h}$. In addition, a low dose dexamethasone suppression test (1 mg overnight) was performed at 1 and 3 months after surgery. In every patient in whom glucocorticoid substitution was started after surgery, we tried to reduce the dose of oral glucocorticoids starting 3 months after surgery and to stop glucocorticoid substitution within 12 months after surgery. After stopping glucocorticoid substitution the integrity of the hypothalamic-pituitary-adrenal axis was assessed in these patients by the insulin-hypoglycemia test (40). In all patients who were in remission of hypercortisolism after pituitary surgery, low dose dexamethasone suppression tests (1 mg overnight) were performed yearly and of course earlier when there was a clinical suspicion of recurrence of the hypercortisolism.

Assessment of the thyrotropic, gonadotropic and somatotropic axis was performed at regular intervals by measuring the serum concentrations of thyrotropin (TSH), free thyroxine (FT4), gonadotropins (LH and FSH), testosterone, estradiol and insulin-like growth factor- 1 (IGF-1). In case of clinical suspicion of growth hormone $(\mathrm{GH})$ deficiency a $\mathrm{GH}$ stimulation test (preferably an insulin-hypoglycemia test) was performed.

\section{Criteria for remission and relapse}

Remission was defined as adequate suppression of plasma cortisol $(\leq 50 \mathrm{nmol} / \mathrm{L})$ after $1 \mathrm{mg}$ dexamethasone overnight determined in the first 3 months after surgery and disappearance of clinical signs and symptoms of hypercortisolism.

Relapse was defined as development of inadequate suppression of plasma cortisol after $1 \mathrm{mg}$ dexamethasone overnight in a patient who was postoperatively in remission according to the above-mentioned criteria.

\section{Assays}

ACTH was measured in EDTA plasma by a two-step immunoradiometric assay (IRMA, Dynotest BRAHMS, Berlin, Germany). Within and between assay coeficients of variations (CV) were $5.8 \%$ and $7.4 \%$ at a level of $2.4 \mathrm{pmol} / \mathrm{L}$ and $4.7 \%$ and $4.0 \%$ at a level of $29.9 \mathrm{pmol} / \mathrm{L}$. A functional detection limit of $0.8 \mathrm{pmol} / \mathrm{L}$ was established. The reference range is 2.2$13.2 \mathrm{pmol} / \mathrm{L}$.

Plasma cortisol was measured by radioimmunoassay. In patients who were treated with metyrapone and/or ketoconazole the radioimmunoassay was done after previous extraction and paper chromatography (41). To summarize briefly, before extraction $3 \mathrm{H}$-cortisol was added to correct for procedural losses. After chromatography, the location of the cortisol zone was identified by radiochromatogram scanning, the zone was cut out and soaked in buffer. The recovered radioactivity was measured by liquid scintillation counting of an aliquot from the eluate. Subsequently, cortisol tracer and antiserum were added and after incubation, free and bound tracers were separated by means of dextran coated charcoal. The antibody bound radioactivity was assessed by liquid scintillation counting of the supernatant. The calculations were performed by special software designed for correction of the mass and radioactive contribution of the recovery tracer in the RIA. Using a sample volume of $0.05 \mathrm{ml}$, the detection limit was $1.4 \mathrm{nmol} / \mathrm{L}$. The between-assay $\mathrm{CV}$ was $5.9 \%$ at a level of $320 \mathrm{nmol} / \mathrm{L}$. Accuracy was assessed over a longer period of time by measurement of QC samples in which the cortisol levels had been established by GC/MS, which resulted in 100.7 $\pm 2.4 \%$ $(\mathrm{n}=40)$ of the target value.

The reference range is $190-500 \mathrm{nmol} / \mathrm{L}$ (at $0800 \mathrm{~h}$ ).

\section{Statistics}

Chi-square tests were used to test for differences in the proportion of patients with macroadenomas, histological confirmation of the ACTH producing adenoma and use of cortisol lowering medication between the 
remission and failure groups. Statistical significance was considered when $P<0.05$ (two-tailed).

\section{Results}

The results of endoscopic transsphenoidal pituitary surgery in the 35 patients with Cushing's disease are shown in Fig. 1. The individual data of the 35 patients are given in Table 1. The mean follow-up was 27 months (range 4 to 81 months; median 20 months). After initial pituitary surgery 25 patients were in remission according to the criteria mentioned above. In two patients (patients 7 and 17) a $1 \mathrm{mg}$ dexamethasone suppression test was not done postoperatively. However, both had a clearly subnormal basal cortisol level postoperatively and went into clinical remission and still received glucocorticoid substitution at the last followup visit. Including these two patients the remission rate in our series was $77 \%$. During the follow-up none of the patients in our series had a relapse of Cushing's syndrome. In 8 patients initial pituitary surgery failed to cure the hypercortisolism. In three of these patients (patients 6,10 and 11) the tumor could not be localized, either preoperatively on MRI or during pituitary surgery, and one patient (patient 18) had a lesion suspect for a microadenoma on the preoperative MRI. No ACTH producing adenoma was found on histological examination of tissue removed during the first surgery in these four patients. Three of them (patients 6,10 and 11) had a second endoscopic pituitary operation between 3 and 11 months after the initial surgery. In none of these patients histological examination of the tissue removed during the second operation showed evidence of an ACTH producing adenoma. Nevertheless, two of them became in remission after the second operation (patients 6 and 10). In the third patient hypercortisolism persisted after the second operation and she finally had a bilateral adrenalectomy eight months later (patient 11). In the fourth patient (patient 18) the second pituitary surgery will soon follow. Four other patients with a failure of the first pituitary operation were treated postoperatively with radiotherapy (patients 4, 9, 21 and 34). Two of these patients had macroadenomas with invasion of the cavernous sinus (patients 9 and 21) and one had a microadenoma on the MRI (patient 4). In one patient the tumor could not be visualized either on the MRI, or during the exploration of the pituitary (patient 34). The presence of an ACTH producing adenoma was confirmed on histological examination in the three patients in whom the tumor was visualized. At the time of the last follow-up visit (45 and 34 months after radiotherapy), two of these patients (patients 4 and 9) were in remission. The second patient with a macroadenoma is improving clinically after radiotherapy. At the moment (11 months after radiotherapy) he uses ketoconazole in decreasing dosage (patient 21). The fourth patient has only recently received radiotherapy and is still receiving ketoconazole (patient 34).

As can be seen in Table 1, there was a gradual increase in the number of patients receiving endoscopic surgery per year. During the first four years after the introduction of the endoscopic technique, in 6 out of 10 patients $(60 \%)$ a remission was achieved after initial pituitary surgery. However, in the following three years a remission was achieved in 21 of the 25 patients (84\%). Remission was achieved in 29 patients $(83 \%)$ after the first or second pituitary surgery. There have been no recurrences in these 29 patients during follow-up.

When comparing the groups of patients with successful and unsuccessful initial pituitary surgery, a macroadenoma was present in $25 \%$ of the patients with unsuccessful and in $14 \%$ of the patients with successful surgery $(P=0.37)$, whilst the percentage of patients that were treated preoperatively with cortisol lowering agents was the same $(85.5 \%$ in both groups). The percentage of patients in whom the presence of an ACTH producing adenoma was confirmed histologically was $81 \%$ in the succesfully compared to $50 \%$ in the unsuccesfully operated patients $(P=0.061)$.

Ten of the 27 patients who had a successful initial surgery had complications perioperatively. Two patients

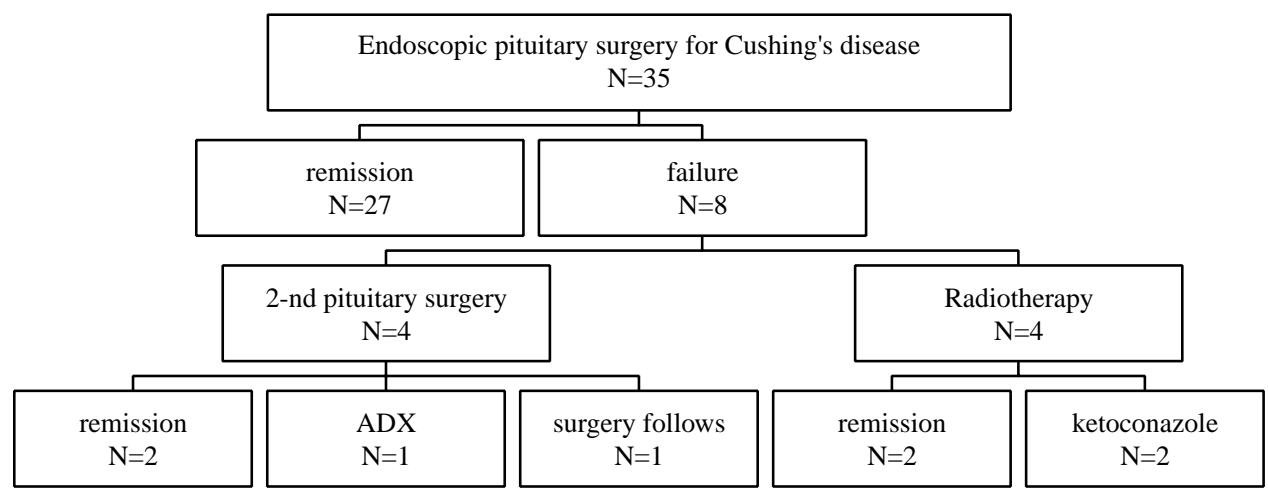

Figure 1 Results of endoscopic pituitary surgery in patients with Cushing's disease (1998-2004). (ADX: bilateral adrenalectomy). 
Table 1 Clinical characteristics of the 35 consecutive patients with Cushing's disease operated by endoscopic transsphenoidal pituitary surgery between 1998 and 2004.

\begin{tabular}{|c|c|c|c|c|c|c|c|c|c|c|c|}
\hline \multirow{2}{*}{$\begin{array}{l}\text { Patient no., gender, } \\
\text { age (years) }\end{array}$} & \multirow[b]{2}{*}{ CLA } & \multirow[b]{2}{*}{ MRI } & \multirow[b]{2}{*}{ SPS } & \multirow[b]{2}{*}{ Year of TS } & \multirow[b]{2}{*}{ Histology } & \multicolumn{2}{|c|}{ Cortisol (nmol/L) } & \multirow[b]{2}{*}{ TS result } & \multirow[b]{2}{*}{ Additional therapy } & \multirow[b]{2}{*}{ Hormona substitution } & \multirow{2}{*}{$\begin{array}{r}\text { Follow-up } \\
\text { (months) }\end{array}$} \\
\hline & & & & & & Basal & After Dex & & & & \\
\hline 1. $m, 35$ & M & - & left & 1998 & + & $<20$ & $<20$ & $\mathrm{R}$ & - & - & 81 \\
\hline 2. $f, 22$ & $\mathrm{~K}$ & $<10$ & left & 1998 & + & 30 & - & $\mathrm{R}$ & - & $\mathrm{E}, \mathrm{GH}, \mathrm{T}$ & 81 \\
\hline 3. f, 46 & M & - & NP & 1998 & + & $<20$ & 40 & $\mathrm{R}$ & - & - & 74 \\
\hline 4. $f, 42$ & $M$ & $<10$ & NP & 2000 & + & 560 & 200 & $\mathrm{~F}$ & CR (45 Gy) & $\mathrm{G}, \mathrm{GH}$ & 57 \\
\hline 5. f, 32 & - & - & NP & 2000 & - & 70 & $<20$ & $\mathrm{R}$ & - & $E$ & 50 \\
\hline 6. f, 45 & $\mathrm{~K}$ & - & right & 2000 & - & 440 & 430 & $\mathrm{~F}$ & TS & $\mathrm{E}, \mathrm{G}, \mathrm{T}$ & 49 \\
\hline 7. f, 44 & $\mathrm{M}$ & $<10$ & NP & 2001 & + & 80 & - & $\mathrm{R}$ & - & $\mathrm{G}$ & $24 \dagger$ \\
\hline 8. $f, 51$ & - & - & right & 2001 & + & 70 & 40 & $\mathrm{R}$ & - & - & 41 \\
\hline 9. $m, 23$ & - & 18 & NP & 2001 & + & 280 & 70 & $\mathrm{~F}$ & RS (20 Gy) & T & 39 \\
\hline 10. $m, 29$ & M & - & left & 2001 & - & 270 & 110 & $\mathrm{~F}$ & TS & $A, G, T$ & 37 \\
\hline 11. f, 36 & $\mathrm{M}, \mathrm{K}$ & - & right & 2002 & - & 400 & 530 & $\mathrm{~F}$ & TS, ADX & $\mathrm{G}, \mathrm{T}$ & 35 \\
\hline 12. $m, 23$ & - & 35 & NP & 2002 & + & 110 & 20 & $\mathrm{R}$ & - & - & 33 \\
\hline 13. f, 62 & $\mathrm{~K}$ & $<10$ & NP & 2002 & + & $<20$ & - & $\mathrm{R}$ & - & G, D & 31 \\
\hline 14. f, 22 & - & - & NP & 2002 & + & 20 & $<20$ & $\mathrm{R}$ & - & $E$ & 27 \\
\hline 15. f, 31 & $\mathrm{~K}$ & $<10$ & NP & 2002 & + & 40 & - & $\mathrm{R}$ & - & $\mathrm{G}, \mathrm{T}$ & 25 \\
\hline 16. $m, 63$ & $\mathrm{M}$ & $<10$ & NP & 2002 & + & $<20$ & 20 & $\mathrm{R}$ & - & A & 25 \\
\hline 17. f, 37 & $\mathrm{~K}$ & $<10$ & right & 2003 & - & 70 & - & $\mathrm{R}$ & - & G & 22 \\
\hline 18. f, 20 & M & $<10$ & right & 2003 & - & 90 & 140 & $\mathrm{~F}$ & TS follows & - & 20 \\
\hline 19. f, 41 & $\mathrm{M}, \mathrm{K}$ & $<10$ & left & 2003 & + & 350 & 20 & $\mathrm{R}$ & - & - & 18 \\
\hline 20. f, 49 & $\mathrm{M}$ & 18 & NP & 2003 & + & 190 & 50 & $\mathrm{R}$ & - & - & 17 \\
\hline 21. $m, 39$ & M & 12 & NP & 2003 & + & 290 & 110 & $\mathrm{~F}$ & RS (35 Gy) & - & 17 \\
\hline 22. $m, 14$ & $\mathrm{M}$ & $<10$ & left & 2003 & - & 20 & 30 & $\mathrm{R}$ & - & T & 14 \\
\hline 23. f, 66 & $\mathrm{M}$ & $<10$ & NP & 2003 & + & 150 & 30 & $\mathrm{R}$ & - & $\mathrm{G}$ & 13 \\
\hline 24. f, 55 & $\mathrm{M}$ & $<10$ & NP & 2003 & + & 90 & $<30$ & $\mathrm{R}$ & - & $\mathrm{T}, \mathrm{D}$ & 12 \\
\hline 25. $m, 38$ & $M$ & - & left & 2004 & - & 200 & $<20$ & $\mathrm{R}$ & - & $\mathrm{T}$ & 11 \\
\hline 26. f, 55 & $\mathrm{~K}$ & 17 & NP & 2004 & + & 90 & $<30$ & $\mathrm{R}$ & - & G & 10 \\
\hline 27. f, 68 & $\mathrm{~K}$ & $<10$ & NP & 2004 & + & 270 & 40 & $\mathrm{R}$ & - & G & 9 \\
\hline 28. f, 64 & $\mathrm{M}$ & $<10$ & NP & 2004 & + & 560 & $<20$ & $\mathrm{R}$ & - & - & 9 \\
\hline 29. f, 53 & $\mathrm{M}, \mathrm{K}$ & - & NP & 2004 & - & 300 & 20 & $\mathrm{R}$ & - & - & 8 \\
\hline 30. f, 37 & $\mathrm{~K}$ & - & NP & 2004 & + & 320 & 20 & $\mathrm{R}$ & - & - & 8 \\
\hline 31. f, 32 & $M$ & $<10$ & NP & 2004 & + & $<20$ & - & $\mathrm{R}$ & - & $\mathrm{G}, \mathrm{T}$ & 6 \\
\hline 32. f, 55 & $\mathrm{M}$ & $<10$ & NP & 2004 & + & 30 & - & $\mathrm{R}$ & - & $\mathrm{G}, \mathrm{T}$ & 6 \\
\hline 33. f, 30 & $\mathrm{M}$ & $<10$ & NP & 2004 & + & 60 & 40 & $\mathrm{R}$ & - & $\mathrm{G}, \mathrm{T}$ & 4 \\
\hline 34. $m, 55$ & M & - & left & 2004 & - & 470 & 160 & $\mathrm{~F}$ & RS (19 Gy) & - & 4 \\
\hline 35. m, 21 & $\mathrm{M}$ & 20 & NP & 2004 & + & 90 & 50 & $\mathrm{R}$ & - & - & 4 \\
\hline
\end{tabular}

f: female; m: male; CLA: preoperative therapy with cortisol lowering agents; M: metyrapone; K: ketoconazole; MRI: magnetic resonance imaging results given as maximal diameter of the visualized tumor in $\mathrm{mm}$, MRI-: no tumor visualized on the MRI; SPS: sampling of inferior petrosal sinuses; left: lateralisation to the left inferior petrosal sinus; right: lateralisation to the right petrosal sinus; NP; not performed tolo pituitary surgery; R: remission; F: failure; CR: conventional radiotherapy; RS: radiosurgery; ADX: bilateral adrenalectomy; A: androgens, D: desmopressin; E: estrogens, G: glucocorticoids, GH: growth horhyroxine; tpatient deceased. 
had mild epistaxis controlled with nasal tampons (patients 12 and 25). In one patient (patient 13), a bleeding originating in the sphenopalatinal artery occurred postoperatively. This required a second exploration with successful coagulation of the artery. In this patient bleeding was not present at the end of the first surgery, most likely due to vasoconstriction by injection of epinephrine around the sphenoid ostium. The patient recovered within a few days after the second operation without other complications. Three patients had mild cerebrospinal fluid (CSF) leakage that resolved spontaneously in two of them within a few days (patients 3 and 23) and in the third patient CSF drainage was performed using a lumbal external drain (patient 22). There were two episodes of sudden drop in blood pressure that occurred one week after surgery (patients 23 and 32) caused by glucocorticoid deficiency as both patients were at that time $48 \mathrm{~h}$ after withdrawal of glucocorticoids and they both recovered shortly after administration of glucocorticoids. Three additional patients received transiently desmopressin due to polyuria that resumed after the first days postoperatively. One patient developed mild hyponatremia two weeks after surgery, probably due to a combination of inappropriate ADH secretion and concomitant use of thiazide diuretics. This resolved within two days after the diuretics were discontinued and after starting water restriction. There has been no complication in the failure group.

According to the last follow-up data, 22 (17 from the remission group and 5 from the failure group) of the 35 patients received substitution therapy for deficiency of one or more hormones. These data are summarized in Table 1 . Of all patients, 34\% required substitution with levothyroxine, $40 \%$ required substitution with glucocorticoids, $17 \%$ received estrogens or testosterone and $5.7 \%$ still required desmopressin. Six of the 14 patients still using glucocorticoids had a follow-up of less than 18 months with glucocorticoid dosages still being tapered, so a definitive statement of their adrenal function cannot yet be made.

\section{Discussion}

In the present study we report the results of endoscopic pituitary surgery in 35 consecutive patients with Cushing's disease operated in our centre. In our seven years experience, remission of hypercortisolism was achieved in $77 \%$ of the patients after the first pituitary operation and in $83 \%$ of the patients after the first and the second pituitary operation taken together. This is the largest reported series of endocrinological results in patients with Cushing's disease operated via the endoscopic technique.

Due to its recent introduction, there are only few reports describing larger series of patients with pituitary tumors operated via the endoscopic technique
$(25,29,35)$. It seems that the endocrine outcomes of the patients reported in these initial series are similar to those achieved by the conventional microscopic technique. Cappabianca et al.(29) reported on 87 patients with various pituitary adenomas, including 8 patients with Cushing's disease, that were treated with endoscopic endonasal transsphenoidal pituitary surgery between 1997 and 1999. As remission criterion for patients with Cushing's disease the authors adopted a restoration of the circadian rhythm of cortisol together with the normalization of urinary cortisol levels. Three of these 8 patients had a macroadenoma, one of whom showed parasellar extension with incomplete third cranial nerve palsy. Among the patients with a microadenoma, one underwent a second operation one day after the first surgery because of residual tumor detected on the MRI. Only one patient (having a microadenoma) of this series remained hypercortisolemic after the pituitary operation and was treated additionally by bilateral adrenalectomy. The authors reported no complications during or after surgery in the patients with Cushing's disease. Jho et al. (25) reported in a series of 128 patients with pituitary adenomas operated by endoscopic transsphenoidal surgery, including 16 patients with Cushing's disease, that $70 \%$ of the patients with Cushing's disease had a (sub-)normal postoperative cortisol level. Although these results seem promising, the number of patients with Cushing's disease in these series was too small and postoperative biochemical evaluation was not extensive.

The short follow-up of the patients in our series, due to the recent introduction of the endoscopic technique in the field of pituitary surgery, does not allow us to make any comments on the long-term remission rates of our patients. As previously shown in other series of patients with Cushing's disease, recurrences may develop many years after apparently successful surgical treatment (1-3, 5, 7-10, 12-15). However, our early postoperative results of endoscopic pituitary surgery in a large number of patients with Cushing's disease are in line with the previous studies, reporting on smaller number of patients $(25,29,35)$ and with the results of other large single center series of patients operated by traditional transsphenoidal pituitary microsurgery previously reported (Table 2). Early postoperative cure rates ranging from 68.5 to $87 \%$ have been reported in those large series $(1-3,5,7-10,12-15)$. These differences in remission rates can be at least, in part explained by the different remission criteria used in those studies. Based on the principle that high preoperative plasma cortisol levels suppress normal corticotroph cell function and that complete removal of a corticotroph adenoma will render the patient ACTH deficient with low to undetectable cortisol levels postoperatively, some authors have adopted as criterion for remission a postoperative plasma cortisol value of $<50 \mathrm{nmol} / \mathrm{L}$ (3, 12, 42). However Yap et al. (3) showed that even a cortisol level $<50 \mathrm{nmol} / \mathrm{l}$ early 
Table 2 Review of the criteria used to define remission of Cushing's disease after pituitary surgery in the most recent published single centre series (1995-2004).

\begin{tabular}{|c|c|c|c|c|c|}
\hline Author & Single surgeon & $N$ & Remission criteria & Perioperative G regimen & Remission \% \\
\hline Sonino, 1996 (14) & Yes & 103 & $\begin{array}{l}3 \text { Regression of clinical signs, UFC }<248 \mathrm{nmol} / \mathrm{l} \text { and } \\
\text { suppressable } C \text { (reference not mentioned) to low dose } \\
\text { Dex } 5-15 \text { days from TS at least } 24 \mathrm{~h} \text { after } \mathrm{G} \text { withdrawal. }\end{array}$ & Not mentioned & 76.7 \\
\hline Petruson, 1997 (4) & No & & $\begin{array}{l}124-\mathrm{h} \text { UFC }<300 \mathrm{nmol} / \mathrm{day} \text { and normal circadian rhythm } \\
\text { of serum C, including a midnight value }<150 \mathrm{nmol} / \mathrm{I} \text { within } \\
5 \text { weeks from TS and } 48 \mathrm{~h} \text { after } \mathrm{G} \text { withdrawal. }\end{array}$ & $\begin{array}{l}100 \mathrm{mg} \mathrm{HC} \text { i.v. on day } 1 \text { and } 50 \mathrm{mg} / \text { day } \\
\text { CA for the next } 7 \text { days }\end{array}$ & 77 \\
\hline Estrada, 1997, $2001(10,45)$ & Yes & & $\begin{array}{l}2 \text { Normal UFC }<331 \mathrm{nmol} / 24 \mathrm{~h} \text {, adequate suppression } \\
\text { of plasma } C \text { to overnight } 1 \mathrm{mg} \text { Dex }(<5 \mathrm{ug} / \mathrm{dll}, 138 \mathrm{nmol} / \mathrm{l}) \text {, } \\
8 \text { to } 12 \text { days after TS, } 24 \mathrm{~h} \text { after } \mathrm{G} \text { withdrawal. }\end{array}$ & $\begin{array}{l}300 \mathrm{mg} \mathrm{HC} \text { on TS day, gradually reduced } \\
\text { till hormonal evaluation. }\end{array}$ & 75.5 \\
\hline Blevins, 1998 (6) & Not mentioned & 96 & $\begin{array}{l}\text { Basal C }<5 \mathrm{ug} / \mathrm{dl} \text { or UFC }<15 \mathrm{ug} / 24 \mathrm{~h} \text {, or suppression } \\
\text { of plasma and urinary } C \text { to Dex within } 6 \text { months after TS. }\end{array}$ & Not mentioned & 85.6 \\
\hline Swearingen, 1999 (15) & No & 154 & $\begin{array}{l}\text { 4 Fasting serum } C<138 \mathrm{nmol} / / \text { and } U F C<55 \mathrm{nmol} / \mathrm{l} \\
\text { within } 10 \text { days after TS. }\end{array}$ & Not mentioned & 87 \\
\hline Chee, 2001 (2) & Yes & & $\begin{array}{l}\text { Resolution of clinical signs, suppression of } \\
C<100 \mathrm{nmol} / \mathrm{l} \text { after } 1.5-2 \mathrm{mg} \text { Dex overnight and } \\
\text { reduction of } \mathrm{C} \text { to normal range for both morning } \\
\text { and midnight values, } 48 \mathrm{~h} \text { after } \mathrm{G} \text { withdrawal, within } \\
5 \text { days after TS. }\end{array}$ & Not mentioned & 78.7 \\
\hline Yap, 2002 (3) & Yes & & $\begin{array}{l}7 \text { Basal } \mathrm{C}<50 \mathrm{nmol} / / \mathrm{l}-4 \text { days after TS, 24-h after } \\
\text { G withdrawal. }\end{array}$ & Not mentioned & 68.5 \\
\hline Rees, 2002 (12) & No & 54 & $\begin{array}{l}4 \text { Basal } \mathrm{C}<50 \mathrm{nmol} / \mathrm{l} \text { within } 1 \text { week from TS, } \\
24 \mathrm{~h} \text { after } \mathrm{G} \text { withdrawal. }\end{array}$ & $\begin{array}{l}100 \mathrm{mg} / 6 \mathrm{~h} \mathrm{HC} \text { i.v. on day } 1 \\
\text { thereafter } \mathrm{HC} \text { substitution. }\end{array}$ & 77 \\
\hline Pereira, 2003 (1) & Yes & & $\begin{array}{l}3 \text { Regression of clinical signs, suppression } \\
\text { of C }<100 \text { nmol/l to } 1 \mathrm{mg} \text { Dex and normal } 24-\mathrm{h} \\
\text { UFC } 6 \text { months after TS. }\end{array}$ & $\begin{array}{l}1 \mathrm{mg} / 12 \mathrm{~h} \text { Dex on day } 1 \text {, gradually } \\
\text { reduced to } 0.5 \mathrm{mg} / \text { day on day } 5 \text {. }\end{array}$ & 72 \\
\hline Rollin, 2004 (13) & Yes & 41 & $\begin{array}{l}1 \text { Clinical remission, } \mathrm{G} \text { dependence, serum } \\
\mathrm{C}<3 \mathrm{ug} / \mathrm{dl}(\mathrm{g} 2,8 \mathrm{nmol} / \mathrm{l}) \text { after overnight } 1 \mathrm{mg} \\
\text { Dex within } 10-12 \text { days after TS. }\end{array}$ & $\begin{array}{l}\text { HC } 100 \mathrm{mg} \text { i.v intraoperatively and } 50 \mathrm{mg} / 6 \mathrm{~h} \text { for } 48 \mathrm{~h} \text {, } \\
\text { followed by prednisone } 5 \mathrm{mg} / \mathrm{day} \text { for } 5-6 \text { days } \\
\text { (17 TS) and no G substitution ( } 28 \mathrm{TS} \text { ). }\end{array}$ & 85.3 \\
\hline Hammer, 2004 (5) & Yes & 289 & $\begin{array}{l}\text { Basal or } 1 \mathrm{mg} \text { Dex suppressed } \mathrm{C}<140 \mathrm{nmol} / \mathrm{l} \text { within } \\
1 \text { week from TS or low/normal plasma } \mathrm{C} \text { and UFC } \\
\text { and no additional therapy within } 6 \text { months. }\end{array}$ & Not mentioned. & 82 \\
\hline
\end{tabular}


after surgery does not always predict the long-term remission of Cushing's disease. Interestingly, Pereira et al. (1) recently found that a fasting cortisol level $<138 \mathrm{nmol} / \mathrm{L}$ measured 3 months after the operation is a stronger predictor for long-term relapse than a plasma cortisol level $<50 \mathrm{nmol} / \mathrm{L}$ measured early postoperatively. As most of our patients were treated preoperatively with cortisol lowering medication, that renders them less prone to hypocortisolism early postoperatively, we adopted as biochemical remission criterion in these patients suppression of the plasma cortisol level to $1 \mathrm{mg}$ dexamethasone overnight.

The endoscopic technique requires the use of refined instruments, specific skills of the pituitary surgeon and a learning curve (20). In our centre endoscopic pituitary surgery was introduced in 1997 but it has been applied in patients with Cushing's disease only since 1998. All operations were performed by the same two experienced neurosurgeons who both were already very familiar with the endoscopic technique. As the number of patients with Cushing's disease operated per year increased, the neurosurgery team became more experienced and the number of 'failures' decreased (success percentages $60 \%$ in patients operated between 1998 and 2001 versus $88 \%$ in patients operated between 2002 and 2004). As in other studies $(6,43,44)$, we found that the remission percentages were worse in patients with a macroadenoma $(66 \%$ vs $79 \%$ in patients with microadenoma) and in those who did not have an ACTH producing adenoma proven on pathology $(50 \%$ vs $84 \%$ in patients with positive pathology findings). While the endoscopic technique offers advantages in removing macroadenomas due to the wide-angle view, one might argue on optical grounds that it would be more difficult to discriminate the microadenomas from the surrounding tissue than when using the binocular microscopic technique. However, apart from the optics other factors may contribute as well to the successful identification and removal of microadenomas by endoscopy, e.g. the superior illumination of the surgical field. In addition, the increased elevation of the patients head and trunk during endoscopic surgery may decrease venous bleeding during surgery, providing thus a better visualization of the surgical field. Our results show that, in the hands of experienced neurosurgeons, similar remission percentages were obtained in patients with both macro- and microadenomas as in previously reported series of patients with Cushing's disease operated by the conventional microscopic technique $(1-3,5,7-10,12-15)$.

In our series there were only few serious surgical complications postoperatively. One serious bleeding requiring a reoperation took place and only one patient had CSF leakage requiring a lumbal external drain, which is similar to the experience of Hammer et al. (5) in their series of 289 patients with Cushing disease treated by conventional microscopic transsphenoidal surgery, in which 13 patients required a drain or surgi- cal repairment for CSF leakage (5). An important aspect that needs to be stressed when comparing the frequency of complications reported in various studies $(1-3,5,7-10,12-15)$ is that, in these studies, different definitions are used for each complication. Moreover, as all of these studies report retrospective results, one must be careful in interpreting and comparing these results that basically rely on the accuracy by which the complications were recorded in each individual patient.

We cannot make a statement on whether applying the endoscopic technique can modify the postoperative hospitalization time. The protocol used in our hospital, both before and after the introduction of endoscopic pituitary surgery, is that all patients treated for Cushing's disease remain under clinical observation for 7 days until the early postoperative endocrine evaluation has taken place. In this way we ensured a uniform and objective early postoperative observation and registration of postoperative events.

In our series the surgery was as selective as possible in order to avoid damaging of normal pituitary tissue. Nevertheless, $63 \%$ of the patients required hormonal substitution therapy with one or more preparations at the time of last follow-up, including those requiring temporary glucocorticoid substitution. When patients requiring only glucocorticoid replacement therapy were excluded, hypopituitarism, defined as proven deficiency of at least one of the pituitary hormones, was present in $48 \%$ of the patients. However, 6 of the 14 patients who received substitution therapy with glucocorticoids at the time of data collection were in the process of decreasing their glucocorticoid substitution. In addition 5 of the patients who were receiving substitution therapy at the time of the last follow-up had a failure of the first pituitary surgery and were treated subsequently with more extensive surgery or additional radiotherapy. Furthermore, there seemed to be more combined hormone deficiencies in the patients operated in the early years (1998-2001). Our data on postoperative pituitary insufficiency are in keeping with results of previously reported series of patients operated by the conventional microscopic technique $(2,3,8,12$, $15,42)$. The rate of hypopituitarism defined as at least one deficient pituitary hormone axis after pituitary surgery ranges from $14-62 \%$ in these previous reports and seems to be related to more extensive surgical approaches.

In our study, inferior petrosal sinuses sampling was not performed in order to identify the side of the pituitary where the adenoma is located, but to confirm the pituitary origin of the hypercortisolism in patients with equivocal results of initial endocrine function tests, regardless the findings on MRI. Only in case of negative MRI investigations and a negative pituitary exploration, a hemihypophysectomy was performed, based on results of ACTH levels at the right and at the left side during inferior petrosal sinus sampling, if 
available. The same strategy has been previously used in other reported series (5).

In conclusion, endoscopic transsphenoidal pituitary surgery, in the hands of experienced surgeons, resulted in our series of patients with Cushing's disease in an excellent early postoperative remission rate which was as good as those previously reported by experienced centres using conventional microscopic techniques. Surgical complications and discomfort for the patients were minimal. The question that remains to be answered is whether endoscopic pituitary surgery will also result in a favourable long-term outcome of patients with Cushing's disease. Furthermore, a randomized clinical trial, comparing endoscopic and conventional pituitary surgery in patients with Cushing's disease, is needed to determine the pros and cons of both techniques.

\section{Acknowledgements}

We gratefully acknowledge Dr. B Haugen UCHSC, Denver, USA for his valuable comments on the manuscript.

\section{References}

1 Pereira A, van Aken M, van Dulken H, Schutte P, Biermasz N, Smit J, Roelfsema F \& Romijn J. Long-term predictive value of postsurgical cortisol concentrations for cure and risk of recurrence in Cushing's disease. Journal of Clinical Endocrinology and Metabolism $2003885858-5864$.

2 Chee G, Mathias D, James R \& Kendall-Taylor P. Transsphenoidal pituitary surgery in Cushing's disease: can we predict outcome? Clinical Endocrinology $2001 \mathbf{5 4} 617-626$.

3 Yap L, Turner HE, Adams C \& Wass JAH. Undetectable postoperative cortisol does not always predict long-term remission in Cushing's disease: a single centre audit. Clinical Endocrinology 200256 $25-31$.

4 Petruson K, Jakobsson K-E, Petruson B, Lindstedt G \& Bengtsson B-A. Transsphenoidal adenomectomy in Cushing's disease via lateral rhinotomy approach. Surgical Neurology $1997 \mathbf{4 8}$ $37-45$.

5 Hammer G, Tyrrell J, Lamborn K, Applebury C, Hannegan E, Bell S, Rahl R, Lu A \& Wilson C. Transsphenoidal microsurgery for Cushing's disease: initial outcome and long-term results. Journal of Clinical Endocrinology and Metabolism $2004 \mathbf{8 9}$ 6348-6357.

6 Blevins L, Christy J, Khajavi M \& Tindall G. Outcomes of therapy for Cushing's disease due to adrenocorticotropin-secreting pituitary macroadenomas. Journal of Clinical Endocrinology and Metabolism 199883 63-67.

7 Barbetta L, Dall'Astra C, Tomei G, Locatelli M, Giovanelli M \& Ambrosi B. Assessment of cure and reccurence after pituitary surgery for Cushing's disease. Acta Neurochirurgica 2001143 $477-482$.

8 Cannavo S, Almoto B, Dall'Astra C, Corsello S, Lovicu RM, De Menis E, Trimarchi F \& Ambrosi B. Long-term results of treatment in patients with ACTH-secreting pituitary macroadenomas. European Journal of Endocrinology 2003149 195-200.

9 Devoe D, Miller W, Conte F, Kaplan S, Grumbach M, Rosenthal S, Wilson C \& Gitelman S. Long-term outcome in children and adolescents after transsphenoidal surgery for Cushing's disease. Journal of Clinical Endocrinology and Metabolism 199782 3196-3202.
10 Estrada J, Garcia-Uria J, Lamas C, Alfaro J, Lucas T, Diez S, Salto L \& Barcelo B. The complete normalization of the adrenocortical function as a criterion of cure after transsphenoidal surgery for Cushing's disease. Journal of Clinical Endocrinology and Metabolism $2001865695-5699$.

11 Pieters G, Hermus A, Meijer E, Smals A \& Kloppenborg P. Predictive factors for initial cure and relapse rate after pituitary surgery for Cushing's disease. Journal of Clinical Endocrinology and Metabolism $1989691122-1126$.

12 Rees D, Hanna F, Davies J, Mills R, Vafidis J \& Scanlon M. Longterm follow-up results of transsphenoidal surgery for Cushing's disease in a single centre using strict criteria for remission. Clinical Endocrinology $200256541-551$.

13 Rollin G, Ferreira N, Junges M, Gross J \& Czepielewski M. Dynamics of serum cortisol levels after transsphenoidal surgery in a cohort of patients with Cushing's disease. Journal of Clinical Endocrinology and Metabolism 200489 1131-1139.

14 Sonino N, Zielezny M, Fava G, Fallo F \& Boscaro M. Risk factors and long-term outcome in pituitary-dependent Cushing's disease. Journal of Clinical Endocrinology and Metabolism 199681 2647-2652.

15 Swearingen R, Biller B, Barker F, Katznelson L, Grinspoon S, Klibanski A \& Zervas N. Long-term mortality after transsphenoidal surgery for Cushing's disease. Annals of Internal Medicine 1999 $130821-824$.

16 Reitmeyer M, Vance M \& Laws E. The neurosurgical management of Cushing's disease. Molecular and Cellular Endocrinology 2002 $19773-79$.

17 Lindholm J, Juul S, Jorgensen J, Astrup J, Bjerre P, FeldtRasmussen U, Hagen C, Jorgensen J, Kosteljanetz M, Kristensen L, Laurberg P, Schmidt K \& Weeke J. Incidence and late prognosis of Cushing's syndrome: a population-based study. Journal of Clinical Endocrinology and Metabolism $2001 \mathbf{8 6}$ $117-123$.

18 Cappabianca P, Alfieri A \& de Devitiis E. Endoscopic endonasal transsphenoidal approach to the sella: towards functional endoscopic pituitary surgery. Minimally Invasive Neurosurgery 1998 $4166-73$.

19 Cappabianca P, Aliferi A, Thermes S, Buonamassa S \& de Devitiis E. Instruments for endoscopic endonasal transsphenoidal surgery. Neurosurgery 199945 392-396.

20 Cappabianca P \& de Devitiis E. Endoscopy and transsphenoidal surgery. Neurosurgery 200454 1043-1050.

21 Cappabianca P, Cavallo LM \& de Devitiis E. Endoscopic endonasal surgery. Neurosurgery 200455 933-941.

22 Jho H-D \& Carrau R. Endoscopic endonasal transsphenoidal surgery: experience with 50 patients. Journal of Neurosurgery 1997 $8744-51$.

23 Jho H-D \& Alfieri A. Endoscopic transsphenoidal pituitary surgery: various surgical techniques and recommended steps for procedural transition. British Journal of Neurosurgery $2000 \mathbf{1 4}$ $432-440$.

24 Jarrahy R, Berci G \& Shahinian H. Assessment of the efficacy of endoscopy in pituitary adenoma resection. Archives of Otolaryngology - Head and Neck Surgery 2000126 1487-1490.

25 Jho H-D. Endoscopic transsphenoidal surgery. Journal of Neurooncology $2001 \mathbf{5 4} 187-195$.

26 Thomas R, Monacci W \& Mair E. Endoscopic image-guided transethmoid pituitary surgery. Otolaryngology Head and Neck Surgery $2002127409-416$.

27 Badie B, Brooks N \& Souweidane M. Endoscopic and minimally invasive microsurgical approaches for treating brain tumor patients. Journal of Neurooncology $200469209-219$.

28 Couldwell W. Transsphenoidal and transcranial surgery for pituitary adenoma. Journal of Neurooncology $200469237-256$.

29 Cappabianca P, Cavallo LM, Colao A, Del Basso De Caro M, Esposito F, Cirillo S, Lombardi G \& de Divitiis E. Endoscopic endonasal transsphenoidal approach: outcome analysis of 100 consecutive procedures. Minimally Invasive Neurosurgery 200245 193-200.

30 Casler J, Doolittle A \& Mair E. Endoscopic surgery of the anterior skull base. Laryngoscope 2005115 16-24. 
31 Cho D-Y \& Liau W-R. Comparison of endonasal endoscopic surgery and sublabial microsurgery for prolactinomas. Surgical Neurology $2002 \mathbf{5 8} 371-376$.

32 Ogawa T, Matsumoto K, Nakashima T, Okano M, Ono Y, Fukushima K, Yuuen K, Akagi H \& Nishizaki K. Hypophysis surgery with or without endoscopy. Auris Nasus Larynx 200128 143-149.

33 White D, Sonnenburg R, Ewend M \& Senior B. Safety of minimally invasive pituitary surgery (MIPS) compared with a traditional approach. Laryngoscope 2004114 1945-1948.

34 Cavallo LM, Briganti F, Cappabianca P, Maiuri F, Valente V, Tortora F, Volpe A, Messina A, Elefante A \& de Devitiis E. Hemorrhagic vascular complications of endoscopic transsphenoidal surgery. Minimally Invasive Neurosurgery 2004 47 145-150.

35 Nasseri S, Kasperbauer J, Strome S, McCaffrey T, Atkinson J \& Meyer F. Endoscopic transnasal pituitary surgery: report on 180 cases. American Journal of Rhinology $2001 \mathbf{1 5} 281-287$.

36 Wood PJ, Barth JH, Freedman DB, Perry L \& Sheridan B. Evidence for the low dose dexamethasone suppression test to screen for Cushing's syndrome-recommendations for a protocol for biochemistry laboratories. Annals of Clinical Biochemistry 199734 222-229.

37 Newell-Price J, Morris DG, Drake WM, Korbonits M, Monson JP, Besser GM \& Grossman AB. Optimal response criteria for the human $\mathrm{CRH}$ test in the differential diagnosis of ACTH-dependent Cushing's syndrome. Journal of Clinical Endocrinology and Metabolism 200287 1640-1645.

38 Biemond P, de Jong FH \& Lamberts SW. Continuous dexamethasoneinfusion for seven hours in patients with the Cushing syndrome. A superior differential diagnostic test. Annals of Internal Medicine $1990112738-748$.

39 Oldfield EH, Doppman JL, Nieman LK, Chrousos GP, Miller DL, Katz DA, Cutler GB Jr \& Loriaux DL. Petrosal sinus sampling with and without corticotropin-releasing hormone for the differential diagnosis of Cushing's syndrome. New England Journal of Medicine 1991325 897-905.

40 Plumpton FS \& Besser GM. The adrenocortical response to surgery and insulin-induced hypoglycaemia in corticosteroid-treated and normal subjects. British Journal of Surgery $1969 \mathbf{5 6}$ $216-219$.

41 MacKenzie M, Hoefnagels W, Jansen R, Benraad T \& Kloppenborg P. The influence of glycyritinic acid on plasma cortisol and cortisone in healthy young volunteers. Journal of Clinical Endocrinology and Metabolism 199070 1637-1643.

42 Trainer P, Lawrie H, Verhelst J, Howlett T, Lowe D, Grossman A, Savage M, Afshar F \& Besser G. Transsphenoidal resection in Cushing's disease: undetectable serum cortisol as the definition of successful treatment. Clinical Endocrinology 199338 73-78.

43 Salenave S, Gatta B, Percheur S, San-Galli F, Visot A, Lasjaunias P, Roger P, Berge J, Young J, Tabarin A \& Chanson P. Pituitary magnetic resonance imaging findings do not influence surgical outcome in adrenocoricotropin-secreting microadenomas. Journal of Clinical Endocrinology and Metabolism 200489 3371-3376.

44 Barrou Z, Abecassis JP, Guilhaume B, Thomopoulos P, Bertagna X, Derome P, Bonnin A \& Luton JP. Magnetic resonance imaging in Cushing disease. Prediction of surgical results. Presse Medicale $1997267-11$.

45 Estrada J, Boronat M, Mielgo M, Magallon R, Millan I, Diez S, Lucas $\mathrm{T} \&$ Barcelo B. The long-term outcome of pituitary irradiation after unsuccessful transsphenoidal surgery in Cushing's disease. New England Journal of Medicine 1997336 $172-177$.

Received 5 December 2005

Accepted 7 February 2006 